by our present imperfect methods, during May and June has been distinct, with few exceptions, but the amount has not been great, the maximum ozone having only been $2^{\circ} \cdot 5$, and that merely on one occasion. So soon as such a stagnancy of the air occurs as to be accompanied with a deficiency in its oxiclating power, practitioners should be on the watch for the occurrence of diarrhoea and cholera, if we are to reason from the characteristic phenomena last year; but as yet there has been no such symptom in the atmosphere.

\section{9. altinuto}

OF THE PRACTICE OF

\section{MEDICINE AND SURGERY IN THE}

\section{HOSPITALS OF LONDON.}

Nulla est alia pro certo noscendi via, nisi quam plurimas et morborum et dissectionum historias, tam aliorum proprias, collectas habere et in
secomparare, MIorgAGN. De Sed. et Cuus. MIorb. lib. 14. Promium.

\section{ROYAL FREE HOSPITAL.}

RUPTURE OF THE LIGAMENTUM PATELEA; RECOVERY.

\section{(Under the care of Mr. T. WAKLEX.)}

Ruptuke of ligaments, more particularly rupture of the ligamentum patellæ, as stated by $\mathrm{Mr}$. T. Wakley a few days ago, is very seldom met with in nosocomial practice; so that the case to which we wish to.day to draw attention is one of those which will repay attention, and be perused with interest. The variety of cases at the different hospitals, it is sometimes objected, are without connexion, but every original or new case must be separated from those which went before, and the highest reward of hospital industry is found in meeting every emergency as it arises.

"Ligaments are the last of all the different parts of the body to be diseased," according to the acute observation of Wickham, " and it is very common to find the ligaments perfect when every other texture is either altered or destroyed ;" and we learn also that the synovial membrane passing sometimes over ligaments, and reflected from the inside of capsules and joints, is more highly oroanized than the so-called membrane over the surface of the cartilages of the articulation itself. All writers on surgery, as Mr. Wakley observed in the present case, demonstrate these facts, as well as the force of muscular action, by the fracture of bones, and more especially by fracture of the patella. In the works of Desault, Petit, Sir Astley Cooper, for instance, we read of numerous examples; but the instances of rupture, or tearing across of the ligament of the patella itself, are very rarely met with indeed, and form by far the exception to a general rule. Desanlt tells us of a soldier who broke his patella by the mere muscular effort of stretching out his foot to kick his sergeant! At the Hôtel Dieu, in operating for calculus in the bladder, it was found in one case that in the kicking of the patient, and spasms of the muscles, both patellæ had got broken across during the operation. While more recently still, within the past twelve months, we have heard Mr. Stanley demonstrate to his class some very singular instances of ligaments being torn from their attachments rather than break across. This action cf "spasm," or of muscular contraction acting on ligaments, as a cause of fracture or dislocation, Mr. Stanley is inclined to consider as too often forgotten or lost sight of. $\mathrm{He}$ has known fracture to oceur in the violent paroxysms of epilepsy; even in the spasms of cholera the ligaments may be torn! Mr. Stanley, from his old recollections, and notes of cases he has known in the practice of Mr. Abernethy or Mr. Lawrence through a series of years, constantly cites in his clinical observations some most striking and apposite cases of tearing out of ligaments or rupture of tendons, all more or less explanatory of Mr. Wakley's case. Thus, a man was brought into St. Bartholomew's Hospital, not with dislocation, but fracture of the leg in two places, the leg being broken by the crush or snap of the ligaments or tendons, caused by kicking at his adversary. In another instance, a bookbinder at work in a room where a large fly-wheel was revolving, happened one day to tie a piece of string round his thumb to remind him of something when he got home. One end of the string, $\mathrm{Mr}$.
Stanley says, got suddenly into the machinery. With the rapidity of thought he attempted to withdraw his arm, but found his thumb gone, and his arm broken in two places, not by direct violence, but by the spasm or drag of the ligaments and tendons. The flexor pollicis longus tendon, which is now pre serred in the museum, was completely drawn out from its origin in the interosseous ligament; the humerus was broken at the deltoid insertion, and the radius and ulna were both twisted by the ligaments. Numerous other instances, such as rupture of the internal lateral ligament of the ankle by a violent twist of the foot outwards, preceding the fracture of the bone, might also be adduced.

According to some recent microscopic examinations of torn ligaments, it appears that inflamed ligaments from rupture are generally found thickened and more pulpy than in their normal condition; thus, perhaps, offering a sort of predisposition to be torn, in preference to the bones being dislocated or fractured.

A very interesting case is given by Sir Astley Cooper, where a patella which had been previously broken, and had united in the usual mode, was found opened up again in after years by accidental ulceration; and by the destruction of the not very highly vitalized parts which had formed the line of ligamentous union. All such cases are different from that under the care of Mr. T. Wakley, to which we wish to draw attention at present. Yet, as was observed by this surgeon, all such injuries reflect more or less light on the obscure diseases of the ligaments of the knee-joint; enlarged on, in their more purely pathological bearings, by Sir B. Brodie, Mr. Coulson, Mr. Stanley, and other writers. The ligamentum patella also forms such an essential or integral portion of the knee-joint itself, that no surgical injury of this part can be treated without due care and precaution. The areolar stissue of the substance of such ligaments, it is further said, under such an accident as the present, becomes highly vascular, often leading to subsequent softening or ulceration, and is very slow in healing by first intention like other parts. This is well shown in a case now under Mr. Stanley and Mr. Paget, where the tendons of the wrist were cut across, and where all the various appliances of gutta percha, leather, \&c., have been nearly exhausted in keeping the parts in apposition.

The serious character of surgical injury of the ligamentum patellæ, if not properly diagnosed, or recognised at first through the odematous swelling and discoloration about the knee, may also be learned from a case cited by Sir Charles Bell, where the substance forming the ligamentous union was so incorporated with the skin, that the latter happening to be lacerated, the entire knee-joint was laid open, and amputation of the thigh became necessary. In this point of view, no case of ruptured ligament, however insignificant in hospital practice it may appear to be, is unworthy of study and attention.

We are indebted to Mr. Turtle, the senior house-surgeon, for the following history of the case:-

John T_- cabman, aged forty-two, was admitted into the accident ward, under the care of Mr. T. Wakley, with rupture of the ligamentum patellæ of the right leg. He is a robust and remarkably healthy-looking man, and has generally enjoyed good health. He says that he was in the act of getting up to the driving-seat of his cab, and had placed his left leg on the wheel, and was raising the other, when he felt something give way at the knee, with a loud report, and felt as thongh a "tight piece of cord had been cut through," after which he was unable to put the right leg to the ground, and a great deal of swelling took place around the joint. The accident occurred at a quarter-past nine A.M., and he was brought to the hospital immediately in a cab. He was seen by the house-surgeon at ten A.M., when the patella was found three inches above its natural position, and a great depression was found imnediately over the joint. A straight splint was applied to the back of thigh and leg, with a cross splint fastened to it behind the knee; the patella was brought into its normal situation by a few turns of a roller from the cross splint. The knee, leg, and foot became enormously swollen, and caused considerable diffi. culty in the after treatment, which consisted of modifications of the above plan. The swelling has subsided, and he can raise his leg unaided. The patella is very nearly in its proper place. A few days since, a bandage of leather, encircling the knee, and provided with lateral and posterior iron rods, was applied, and, aided by this simple but most effectual means, he can support the weight of his body upon the affected leg.

In anatomical language, perhaps, the ligamentum patella is not a ligament at all, but is rather the prolongation of the tendon of the extensor musscles of the thigh, so familiar in pathological specimens, and in the operating theatre, extending down the thigh towards the tubercle of the tibia. 
This so-called ligament presenting the patella as a " sesamoid bone," developed in the tendon for the defence of the front of the knee-joint. The true ligaments within this joint being, on the other hand, the crucial transverse and coronary inside, those on the posterior being the well known ligament of Winslow, the tendon of the popliteus, \&c. This arrangement of the patella, extensor tenclons, and parts inferiorly in serted, with a large bursa and mass of loose fat projecting into the cavity of the joint below the patella, as well as the large pouch of synovial membrane inmediately beneath the ex tensor tendon, and in front of the lower extremity of the femur, are all worthy of being kept in mind in considering the gravity of such an accident, which may, from external causes and mechanical injury, implicate all these parts, or the ligamentum patella alome, as in the present case.

\section{ST. BARTHOLOMEW'S HOSPITAL.}

RUPTURE OF THE POSTERIOR TIBIAL ARTERY; DELIGATION UNSUCCESSFUL.

(Under the care of Mr. M' WhunNIE, )

IN connexion with a severe case of secondary hataorrhage given by Mr. Skey in extenso in ThE LANCET of June 9th, the accompanying instance of rupture of the posterior tibial artery may be found instructive. In the following operation the artery was deligated without the surgeon being positively aware of the exact vessel torn, except from the presumptive evidence afforded by absence of pulsation, the excessive pain, and the nature of the accident, as well as by the large quantity of blood thrown aut from the artery; indeed, for some hours the question was in the balance as to whether the limb should be amputated, or the nature of the injury of the vessels in the ham ascertained first. The latter proceeding was, how ever, adopted, as not necessarily excluding the former, in case there should be necessity for it. The patient, too, was a brewer's drayman-a class who bear operations very badly.

R. $\mathrm{S}-$, aged twenty-eight, was admitted into $\mathrm{St}$. Bartho lomew's Hospital, one day last month, in a state of great ex haustion. The history given of the accident was the following:- As he was driving his dray in the street, the horses started off, and his left leg got crushed between the front plank of the dray and a gate-post. The limb almost irnmediately began to swell; and, two hours after the accident, it was thought better to carry the man to the hospital. The limb was then swollen, tense, and cold, more especially below the knee, where the contrast as to cold was most marked, when comparison was made, to the warmth of other parts of his body. The general appearance of the man was not unlike that of a soldier who had received a severe injury by a cannon-shot in battle. He was as if suffering from slight concussion. He referred all his pain to the calf of the leg; the limb, he said, felt "numb" as to external sensation, but the bursting pain internally was very severe. After the most careful examination of the parts, no pulsation could be detected in either of the main arteries, the anterior or posterior tibial. The pain and swelling of the calf, as well as the tension of the popliteal region, were increasing every hour, tightening the limb as though it would burst. The foot was also perceptibly more cold, and tending, it was feared, towards gangrene. The man's pulse had quickened; his body, however, was warmer. As no time was to be lost, Mr. M'Whinnie, in consultation with some of his colleagues, de cided to make a further exploration of the injury, under the effects of chloroform; it being highly probable the posterior tibial artery was injured, if not entirely torn across, with hæmorrhage into the surrounding parts. It was decided to act on this supposition; and, taking into the calculation the unhealthy condition of brewers' draymen in general, it was deemed better not to amputate the limb except that proceed ing should be imperatively called for.

The operation commenced as soon as the man was under the influence of chloroform. An incision, about four inches long, was first carefully made in the popliteal space, exposing the popliteal artery, which appeared pulsating naturally; the popliteal vein also was apparently sound. A large quantity of blood, however, was extravasated into the parts, as well as round the internal head of the gastrocnemius muscle, which was ruptured. A large vein was seen, which at one moment it was thought might be the source of the hæmorrhage; but tracing the artery down, it was found that all pulsation ceased at a given part. It now appeared plainly that the posterior tribial artery had suffered the injury. On further extending the examination this artery was found pulsating for about half an inch only below the bifurcation of the popliteal, where it became contracted and pulseless. As no wound was percepti- ble, Mr. M'Whinnie next directed his attention to the point where the peroneal artery is given off, and hoping that the wound might be below this point, a ligature was placed round this vessel, and another ligature higher up, about four lines from the bifurcation of the popliteal, around the posterior tibial. Whilst under the influence of the chloroform, all these parts were brought into view, as well as the anterior tibial artery, which had almost by a miracle escaped. The wound having been finally brought together by one strip of plaster, and covered with wet lint, the patient was removed to bed, where the parts were wrapped in cotton wool, and the limb raised. A'bout an hour afterwards, as the effect of the chloroform wore off, he became very restless, and was ordered thirty drops of tincture of opium. He had small quantities of brandyand-water through the night.

Next day, we found that he had had but little sleep; and, twelve hours after the operation, he was found starting up in bed and rambling. His face was flushed and hot, eyes suffused, expression disturbed, skin hot, pulse 130 to 140 , full, jerking, and easily compressible. He was ordered another opiate. Four ounces of brandy to be given with water from time to time, in the intervals of feeding him with beef-tea; the latter the poor fellow took readily. He soon, however, began to sink, and died thirty-two hours after the operation.

The post-mortem, twenty four hours afterwards, showed the limb extensively ecchymosed. The state of the arteries of the part first attracted attention. The anterior tibial, though surrounded with some effused blood, was entire and normal through its whole conrse; the interosseous ligament and tibialis anticus were more or less torn, as were also the hamstring tendons and muscles. Blood was effused all along the sheaths of the popliteal and sciatic nerves. The chief source of the evil in the case, however, presented itself very soon, in a small ragged opening in the posterior tibial artery, just below the ligature on its anterior aspect; below this again, the artery seemed sound. All the other organs of the body were, comparatively speaking, healthy. The bones of the leg and knee were all sound. The absence of pulsation in the anterior tibial was due to the pressure of the extravasated blood, the artery having been burst or ruptured by the original crush of the limb in a bent position against the plank of the dray.

\section{LONDON HOSPITAL.}

CASE OF CLOSED PUPIL COMIPLICATED WITH CATARACT; THREE OPERATIONS; RECOVERY.

(Under the care of Mr. Critchetr.)

WE have witnessed a case which has been operated on at this hospital twice within the last few weeks, which presents some new features in ophthalmic practice. The favourable result, as Mr. Critchett explained, arose from his not doing too much at one time, but "breaking up," as it were, the danger by a series of operations at distant and distinct intervals, each operation perfectly different from the other, yet each suggesting points of practical value in the management of similar conditions. The following abstract of the case will make the subject clear:-

Mary Anne A - aged twenty-eight, was attacked a year ago with acute inflammation of the right eye, followed by sloughing of the cornea and ultimate shrinking of the globe. About six weeks subsequently to this attack, the left eye was similarly inflamed, and the result was a penetrating ulcer of the cornea at its centre, with complete adhesion of the pupillary margin of the iris to the corneal cicatrix, which was large and dense. The anterior chamber of the eye was nearly obliterated, but the cornea was bright round the scar; the iris also could be seen in a healthy condition, with its fibres tightly drawn and attached to it all round. In a word, she was entirely blind of one eye, and so blind of the second that she could not perceive any object, and was led about by her friends. She came under Mr. Critchett's care, at the London Hospital, early in June of the present year, having been blind about eight months. At the last operation, a few days ago, it was very interesting to witness her joy when a piece of torn capsule was removed, and she could see everything as plainly, she declared, as ever she did, and walked back to her ward without help.

The first step towards restoration of sight was the formation of an artificial pupil. This was done in the following manner: - The patient being under chloroform, and the globe exposed by means of the wire speculum, (vide THE LANCET, vol. i. 1855, p. 507,) a small opening was made in the cornea close to its junction with the sclerotic, the small "canular" forceps were introduced, and a strip of iris was drawn away from its attach- 